\title{
Research on Mixed Mode Teaching of C Language Programming
}

\author{
Zenghui Zhao \\ School of Intelligence Science and Information Engineering, Xi'an Peihua University, Xi'an, China \\ 296883619@qq.com
}

Keywords: C language; course teaching; mixed teaching; MOOC

\begin{abstract}
C language programming" is an indispensable basic professional core curriculum in engineering education. It can cultivate students' programming ability in thinking, designing, writing and debugging. This paper takes the $\mathrm{C}$ language programming as an example, analyzes it from the teaching methods such as micro-class, flipping classroom, MOOC, etc., and gives the implementation process of the hybrid teaching method. It will greatly help students improve their self-learning ability, hands-on ability, students' interest in learning, enthusiasm and initiative, and provide good ideas for program design curriculum reform.
\end{abstract}

\section{Introduction}

"C language programming" is the first program design course for students majoring in engineering. The course has more learning content, and the logic of the algorithm is strong. The knowledge points are closely related to each other. The knowledge of follow-up knowledge points has been learned before. The mastery of content is relatively high, the concept is abstract and complex, there are many grammars, and the programming specification is flexible and error-prone. This article summarizes some feasible teaching methods through years of practical teaching. In the reform of many teaching methods, the hybrid teaching is the combination of online and offline teaching through a multimedia network teaching platform, using diverse courseware, video and other materials, flipping the classroom, grouping exercises, scoring each, and communicating offline. Mode analysis and can achieve better teaching results.

\section{Analysis of Teaching Status of "C Language Programming"}

"C language programming" courses in addition to learning more content and more logical algorithms, but also from the basic differences in the students, the teaching process is often difficult to teach teachers, students learn difficult, interest is not big and so on. In the summary analysis of the teaching process, the main problems include:

\subsection{Knowledge and scattered}

The course has a lot of knowledge, dispersal, and strong theory, which makes it impossible for teachers to understand all the knowledge within a limited time. In the process of teaching implementation, the above points make the selection of teaching content very difficult, not to mention the ability to teach teaching knowledge in the classroom with high quality.

\subsection{Poor student motivation}

The "C language programming" course is a highly practical course that focuses on solving problems and cultivating the ability to practice on the machine. The student-centered teaching method is to enable students to continuously acquire a sense of accomplishment in the process of practice, thus fundamentally eliminating the fear of $\mathrm{C}$ language and enhancing their enthusiasm for learning.

\subsection{Differences in student base and poor learning initiative}

Due to the imbalance in the development of computers across the country, the level of computer 
basics among students varies greatly, and the same grade in the same year will be different in the same grade in universities, and it is difficult to teach students in accordance with their aptitude. At the same time, all students adopt the same teaching content as the traditional curriculum setting model, not only has the basic quality of the students, but also led to the basic poor students have a sense of frustration, reducing the students' prosperity.

\section{Blending Teaching Method Based on Flipping Classroom}

Based on the characteristics of the curriculum, the level of students' knowledge, the teaching content is reasonably planned, and advanced teaching methods and teaching methods are used to organize the teaching, so as to effectively improve students' interest in learning and learning effects. To cultivate students' programming ability is the teaching reform of this course. The main problems faced. This article attempts to use microteaching, flipping the classroom, MOOC and other teaching modes in the "C language programming" teaching, combined with the traditional face-to-face method, the use of case-based problem-oriented learning to mobilize the students' enthusiasm for learning, improve the teaching level and teaching of the teaching staff. effect.

\subsection{Micro-curriculum}

The micro-curriculum enables students to have more initiative, and autonomously digging and learning the required knowledge in the process of learning. This not only saves time, but also enhances learning efficiency. Excite interest in learning. The "C language programming" curriculum uses micro lessons. Students learn the difficult points of self-teaching through micro lessons. Through the guidance of teachers and the collaborative learning among students, they master and internalize knowledge and achieve the first lesson after learning. Class reversal.

\subsection{Flipping the classroom}

The flipping class was introduced into the "C language programming" course to enable students to have a better understanding and mastery of the theoretical knowledge points. The knowledge points of the previous and the following chapters were linked together to form a whole, such as the use of sequential structures in the array, selection Structure and loop structure allow students to deeply understand the idea of programming. Through the introduction of feedback and diversified evaluation mechanisms, students can increase participation and meet the needs of students' individualized learning, which is conducive to better interaction and communication between teachers and students.

\subsection{MOOC-based mixed learning teaching model}

By making full use of various resources through reasonable instructional design and integrating MOOC learning into classroom learning, students can finish tasks assigned by the teacher or perform video learning, complete homework, practice and periodical tests, etc., in a planned manner without limitation of time and space. Through the Internet, tutors can use a fixed-time method to communicate, answer questions, and answer replies. Students can also view student learning records. Basically, it can achieve some real-time recording functions, so that teachers can keep abreast of the students' online learning situation and students' knowledge of the knowledge unit.

\section{Implementation of "C Language Programming" Mixed Teaching Method}

\subsection{Pre-school tasks and learning}

Pre-school teachers mainly produce micro-teaching video, arranging task sheets and pre-class preparation reports, and task sheets and pre-study report forms are distributed to students one week in advance.

(1) The video production of the micro-curriculum includes content selection, introduction of micro-curriculum, instructional course design and micro-curricular implementation. Micro-curriculum design should choose the common, representative, typical knowledge points or a 
key and difficult problem in the basic structure of program design. The content should be "small and refined". Video is usually around 10 minutes and 15 minutes is the upper limit. Using the review introduction and problem introduction method, review the introduction method to review the contents of the class once again. The problem introduction method passes specific questions and causes students' attention and thinking.

(2) The task list mainly includes three aspects: learning tasks, content goals, and discussion topics. Taking the loop structure chapter as an example, the teaching tasks include mastering the basics of the $\mathrm{C}$ language cycle structure design grammar, programming the loop structure program in the $\mathrm{C}$ language compiler, and mastering the programming applications for, while, and do...while statements. The teaching content is to understand the loop structure statement format and execution flow by watching the related micro video.

(3) Students prepare and study according to the teacher's requirements and fill in the pre-report report form. The preview report includes the results of the preparatory study and questions, the assessment results for each member of the group, the student's feedback on study time, difficulty of learning, and comments and suggestions. The results of the preparatory study and the problems that exist indicate that students find out their own problems based on the content of the preview. 6 students, one group, according to everyone's mastery and preparation of knowledge of the task list to each team member $\mathrm{A}, \mathrm{B}$ or $\mathrm{C}$ results, the final student sums up the time spent learning the task list, learning difficulty is difficult, difficult and easy Opinions and suggestions refer to suggestions for task assignments for teachers.

\subsection{Teaching Design in Class}

The pre-report report is received on the day before the class starts. The teacher prepares the classroom instruction according to the results of the student's preparation report. The student's classroom teaching consists of three parts: sorting out knowledge, pre-learning task check and discussion of difficult problems. Or, for example, in the chapter on circular structure procedures, this section will improve the effectiveness of teaching through the combination of flipped classrooms and case-based problem-based learning methods.

(1) Combine the knowledge to explain the teacher, explain the basic knowledge of the cyclic structure design syntax on the task list, the format, execution flow, and programming application of the three loop statements for, while, and do...while statements.

(2) Pre-learning tasks The task checks mainly check the questions that the students did not ask. The method of importing case questions checks whether the students have mastered the questions and some students will answer them. For example, think of for, while, and do...while What are the differences between the three loop statements?

(3) The discussion of difficult issues is the focus of the classroom. Teachers should design effective teaching activities based on the questions raised by the students. The students' difficult questions are three types of looping statements: step-type loops, while-type loops, and do-while-type loops.

\subsection{Course Evaluation}

This article emphasizes the diversification of evaluation content and the diversification of methods, paying more attention to students' practical ability and the development of innovative spirit, positive emotional experience and learning interest, and is no longer limited to the evaluation of academic achievement. The evaluation methods of this paper mainly include the evaluation of results and the evaluation of attitudes. The two evaluations are sometimes related to each other.

(1) The evaluation of the results is mainly the pre-report report form and the evaluation of the test applet. The pre-report report is used to check the students' completion of the pre-class task learning sheet. Mainly based on the percentage of completion of the learning content, students self-evaluation and the same group of students to comment on the performance of their own activities. The test applet is first evaluated by itself, and finally evaluated by the teacher through a demonstration. The evaluation is mainly based on the idea of the program and the answer to the question. 
(2) Attitude evaluation refers to the sampling of student's attendance, class participation, opinions, and team cooperation. Mainly from whether they can seriously participate in cooperation and exchanges with other students, listen carefully to other students' opinions, express their opinions and opinions, work with other students to solve problems together, cooperate with other students, and be able to clarify and assume their own division of labor and ability. Students live in harmony, with team awareness, ability to follow the rules of classroom discipline, collaborative learning activities of the group, and the ability to actively help others in peacetime.

\section{Points to reflect}

\subsection{Teachers' requirements}

The main practitioner of flipping the classroom is the teacher. Therefore, the teacher must first understand the theoretical basis and implementation process of flipping the classroom, understand the information technology, and actively participate in the classroom reform practice. In the traditional classroom, classroom discipline is not a problem. In flipping the classroom, the students relax the discussion. The classroom discipline requires the teacher to have a strong management ability.

\subsection{Student participation}

Flipping the classroom requires the active participation of students. Learning from pre-teaching to post-secondary education is an important feature of flipping classroom reforms. Only the full participation of students, full participation and effective participation can effectively implement the flipping of the classroom. Teachers need to guide students and design effective teaching goals and teaching activities so that students and teachers can work together.

\subsection{Platform}

The flipping classroom breaks the traditional classroom teaching mode, puts the knowledge transfer into the class, and the absorption and digestion of knowledge in the class. This requires a platform suitable for this reform. Teaching teacher-student interactive platform is suitable for flipping classroom teaching mode. It can publish and complete learning tasks in various forms. The teachers and students are easy to operate and the platform is mature and recognized by users.

\section{Summary}

The common problem in the teaching of "C language programming" is that the course is theoretically strong, abstract and difficult to understand and has many knowledge points. In this paper, micro lessons and flipping classrooms are used in the teaching of $\mathrm{C}$ language programming. The implementation of the mixed method of " $\mathrm{C}$ language programming" based on flipping classrooms is specifically described, including pre-class knowledge preparation and classroom flipping. Design of teaching and general evaluation methods. "C language programming" extra-curricular learning, curriculum reversal classroom, etc. provide teachers with a new platform and window to evaluate students. Through this platform and window, teachers can see students' participation, learning interest, psychological quality, and cooperation awareness. Practical skills and innovative spirits will enable students to have a more objective and comprehensive assessment. Finally, we reflect on the main points of implementation of the hybrid method, which provides ideas for the curriculum design curriculum reform.

\section{Reference}

[1] Wang Junying, Ma Hongmei. Problems and Countermeasures in C Language Programming Teaching [J]. Educational Theory and Practice, 2015(3): 63-64.

[2] Xie Huiyuan, Li Yanting. The distributary and development of teachers of ideological and 
political theory under the mixed teaching mode. Journal of National Academy of Education Administration, 2016(03):26-30.

[3] Hu Tiesheng, Zhou Xiaoqing. Status Analysis and Development Countermeasures of Micro-curricular Construction in Colleges and Universities [J]. Modern Educational Technology, 2014(2):5-13.

[4] Ruan Chenglin, Yu Huaping. Curriculum Teaching Reform in the "Internet +" Age [J]. Journal of Inner Mongolia Normal University (Education Science Edition), 2016(4):71-73.

[5] Li Xiying. Turning lessons and high school political lesson teaching innovation - Taking a "basic" lesson as an example [J]. Journal of Hebei Normal University (Education Science Edition), 2016(2):99-104. 